Check for updates

London

Cite this as: BMJ 2021;373:n1422 http://dx.doi.org/10.1136/bmj.n1422 Published: 02 June 2021

\title{
Covid-19: PPE guidance is upgraded as evidence of airborne transmission grows
}

Ingrid Torjesen

More NHS staff caring for patients with suspected or confirmed covid-19 will have access to higher grade personal protective equipment (PPE), including $\mathrm{FFP}_{3}$ masks, under updated NHS guidance on covid-19 infection prevention and control. ${ }^{1}$

Issued this week, the updated guidance obliges NHS organisations to assess the risk that covid-19 poses to staff and to act to mitigate any risks, such as by providing higher grade PPE including $\mathrm{FFP}_{3}$ masks. These risk assessments should include evaluations of ventilation, operational capacity, and the prevalence of infections including new variants of concern in the local area.

The guidance also provides updates on the use of valved respirators and upper gastrointestinal endoscopy, advising that extended use of gowns must be minimised, with sessional use taking place only in areas where all patients have confirmed covid-19.

The BMA, which has led calls for better PPE throughout the pandemic, ${ }^{2}$ described the updated guidance as "a step in the right direction."

The association's council chair, Chaand Nagpaul, said, "Crucially, it recommends that respiratory PPE, such as FFP3 masks, must be considered where the threat from passing on covid remains high, and should not be limited to those areas where 'aerosol generating procedures' are taking place.

"This means extending their use to those staff whose exposure to airborne particles from a patient is no less, and whose risk of contracting covid is therefore no less than for those engaged in those procedures classified as [aerosol generating].”

He added, "Despite the majority of staff now having been vaccinated with two doses, it is important that those working on the front line should be given stronger guarantees with appropriate PPE, rather than just surgical masks, given that no vaccine provides complete protection."

\section{Risk assessments}

The guidance update follows a review by the Scientific Advisory Group for Emergencies (Sage) published in April, which found that while respiratory diseases were "conventionally classed as either airborne or droplet in a clinical context," current evidence suggested that SARS-CoV-2 fell between these two categories with transmission "possible through inhalation and mucous membrane exposure to a range of particle sizes, as well as potentially through fomites." 3

Sage said that the decision to use $\mathrm{FFP}_{3}$ respirators should be based on a risk assessment that considers the interaction with a patient, the duration and proximity of exposure, whether there is good fitting and mask adherence, whether staff are routinely wearing eye protection, and whether patients wear masks.

However, Pat Cullen, the Royal College of Nursing's acting general secretary and chief executive, said that the guidance "focuses too much on aerosol generating procedures as the main risk and falls short of the precautionary approach we have been advocating," adding that it left many workers in adult social care insufficiently protected.

"Those working in community settings, care homes, and many other areas are being let down and remain unsure how best to protect themselves," said Cullen. "As we see new variants of concern emerge, we continue to demand that $\mathrm{FFP}_{3}$ masks are made more widely available and increased levels of ventilation as a standardised approach. This is in line with the advice from the World Health Organization and the Centers for Disease Control and Prevention on the risk of aerosol transmission."

The updated guidance applies to NHS and independent hospitals, GP surgeries, mental health and learning disability settings, and care homes, but it does not apply to adult social care settings in England.

1 Department of Health and Social Care, Public Health Wales, Public Health Agency Northern Ireland, Health Protection Scotland/National Services Scotland, Public Health England, NHS England. Covid-19: Guidance for maintaining services within health and care settings-infection prevention and control recommendations (version 1.2). 1 Jun 2021. https://assets.publishing.service.gov.uk/government/uploads/system/uploads/attachment_data/file/990442/Infection_Prevention_and_Control_Guidance_for_maintaining_services_with_H_C_settings.pdf.

2 lacobucci G. Covid-19: Doctors' leaders call for revised PPE guidance to reflect new variants. BMJ2021;372:n146. doi: 10.1136/bmj.n146 pmid: 33452010

3 Mahase E. Covid-19: Wider use of FFP3 masks may be needed because of airborne transmission, say scientific advisers. BM/2021:373:n1089. doi: 10.1136/bmj.n1089.

This article is made freely available for use in accordance with BMJ's website terms and conditions for the duration of the covid-19 pandemic or until otherwise determined by BMJ. You may use, download and print the article for any lawful, non-commercial purpose (including text and data mining) provided that all copyright notices and trade marks are retained. 